\title{
ELECTROCARDIOGRAPHIC CHANGES FOLLOWING RABBIT CORONAVIRUS- INDUCED MYOCARDITIS AND DILATED CARDIOMYOPATHY
}

\author{
Lorraine K. Alexander ${ }^{1}$, Bruce W. Keene ${ }^{2}$ J. David Small ${ }^{1}$, Boyd Yount \\ Jr. ${ }^{1}$ and Ralph S. Baric ${ }^{1}$ \\ 1 Program in Infectious Diseases, Department of Epidemiology, University \\ of North Carolina at Chapel Hill, Chapel Hill, NC 27599-7400, U.S.A. \\ ${ }^{2}$ College of Veterinary Medicine, North Carolina State University, Raleigh, \\ NC 27606, U.S.A.
}

\begin{abstract}
Rabbit Coronavirus (RbCV) infection was divided into two phases based upon day of death and pathologic findings. During the acute phase (days 2-5) heart weights (HW) and heart weight-to-body weight $(\mathrm{HW} / \mathrm{BW})$ ratios were increased with striking dilation of the right ventricle. These changes as well as increased dilation of the left ventricle were especially pronounced during the subacute phase (days 6-12). Myocytolysis, pulmonary edema, and degeneration and necrosis of myocytes, were seen during both phases. Myocarditis, pleural effusion, calcification of myocytes, and congestion in the liver and lungs were seen in the subacute phase. Electrocardiograms (ECGs) exhibited low voltage, nonspecific ST-T wave changes, sinus tachycardia, occasional ventricular and supraventricular premature complexes and $2^{0} \mathrm{AV}$ block consistent with myocarditis and heart failure. Forty-one percent of the survivors exhibited increased HW and HW/BW ratios, biventricular dilation, interstitial and replacement fibrosis, myocyte hypertrophy and myocarditis. ECGs exhibited nonspecfic ST-T wave changes, sinus arrhythmia, occasional ventricular and supraventricular premature complexes and $2^{\circ} \mathrm{AV}$ block. These data suggest that $\mathrm{RbCV}$ infection may result in viral myocarditis and heart failure with a proportion of survivors progressing into DCM.
\end{abstract}

\section{INTRODUCTION}

Virus infection has long been associated with heart disease in both man and experimental animals. Picornaviruses are commonly implicated in $20-30 \%$ of all diagnosed cases, but the etiology of viral myocarditis is usually not determined. Myocarditis probably develops in about $2-5 \%$ percent of persons after viral infection ${ }^{1}$. Viral myocarditis is usually characterized by a benign course of vague flu-like symptoms. Laboratory findings may include electrocardiographic abnormalities, elevated serum concentrations of myocardial enzymes and serological evidence of recent viral infection 1,2 . While the vast majority of patients with viral myocarditis appear to recover without residual heart damage, the disease occasionally progresses to congestive heart failure (CHF), arrhythmias and death 1,2 .

Viral myocarditis has also been implicated as a potentially important etiologic factor in the development of dilated cardiomyopathy (DCM), a primary myocardial disease characterized by progressive ventricular dilation and systolic dysfunction $1,2,3$. DCM is a devastating disease often accompanied by a variety of nonspecific electrocardiographic 
abnormalities, with death generally occurring either suddenly (presumably as a result of arrhythmia) or as the result of progressive heart failure in $50 \%$ of patients within 2-3 years of diagnosis. Myocyte hypertrophy, fibrosis and occasionally active myocarditis are found upon pathologic examination ${ }^{3}$. Virus is usually not isolated from patients with $\mathrm{DCM}_{3}$ but serological studies suggest that viral infection maybe an important initiating event ${ }^{2}$. Most of our understanding of the mechanism by which viruses cause heart disease has come from studying animal models 1 . The two most extensively studied animal models include the coxsackievirus B3 (CBV) and encephalomyocarditis virus (EMC) murine models of myocarditis and DCM 4,5. However the mechanisms by which these viruses induce heart disease remains highly controversial and more animal models for human heart disease are needed 1 . Our laboratory has established an animal model system for myocarditis, CHF and DCM following rabbit coronavirus (RbCV) infection 6,7,8. In this study we examined the electrocardiographic changes associated with the infection.

\section{METHODS}

\section{Infection, Pathologic and Morphometric Studies}

Seventy nine male New Zealand White rabbits were inoculated intravenously via the marginal ear vein or intramuscularly with $0.2 \mathrm{ml}$ of a $\mathrm{RbCV}$ stock containing $10^{3}-10^{4}$ $\mathrm{RID}_{50} / \mathrm{ml}$ as previously described 6,7 . The hearts of all animals were removed, weighed, and then fixed with $10 \%$ phosphate buffered formalin. The hearts were sectioned transversely at the widest dimensions of the ventricles, embedded in paraffin, and stained with hematoxylin-eosin, von Kossa's method or Masson's trichrome stain. Lung and liver sections were also stained with hematoxylin-eosin. The areas of the ventricular cavities, the thickness of the cardiac walls, and the myocyte diameters were determined using the Image Measure sof tware morphometry system or a computerized Zeiss Videoplan-1 digital morphometry system as previously described 6,7 . All morphometric measurements were statistically analyzed and are presented as mean \pm SD. Measurements from animals dying from $R b C V$ infection were analyzed by Student's $T$ test for unpaired observations. Measurements from chronic animals were analyzed by a one-way analysis of variance with a post-hoc contrast.

\section{Electrocardiogram Studies}

Serial electrocardiograms were performed on 13 rabbits infected with $\mathrm{RbCV}$ and on 3 uninfected controls. ECGs were taken using a Grass model 7B polygraph (Grass Instrument Co. Quincy, MA.). Alternatively, a three channel microcomputer augmented cardiograph I (MAC I) digital transmitter, recording unit (Marquette Electronics Inc. Milwaukee, WI) was used. With the Grass polygraph, ECGs were recorded at $50 \mathrm{~mm} / \mathrm{sec}$ with the recorder calibrated to $1.0 \mathrm{mV} / 20 \mathrm{~mm}$. With the MAC I, ECGs were recorded at both 25 and $50 \mathrm{~mm} / \mathrm{sec}$ with the recorder calibrated to $1.0 \mathrm{mV} / 10 \mathrm{~mm}$. Baseline ECGs were recorded on all rabbits for several days prior to infection. ECGs were recorded twice daily from day 3-12 and then at regular intervals through day 30 after infection. All measurements were made in lead II and included heart rate (HR), duration and voltage. In addition, readings from 9 animals were examined for any disturbances of conduction, rhythm and repolarization.

\section{RESULTS}

\section{Clinical and Pathologic Results}

Following $\mathrm{RbCV}$ inoculation into 79 rabbits, twenty-four (30\%) of the animals died between days 2-5 (acute) and twenty-four (30\%) between days 6-12 (subacute). Animals dying during the acute phase had enlarged hearts, dilation of the right ventricle, pulmonary edema, and degeneration and necrosis of myocytes. Ascites, pleural effusion, pulmonary edema, enlarged hearts, biventricular dilation and venous congestion in the liver and lungs was seen in animals dying in the subacute phase. The principle pathologic 
lesions in the subacute phase included myocarditis, calcification of myocytes and increased severity of myocyte degeneration and necrosis 6 .

The heart weight and heart weight-to-body weight (HW/BW) ratios for animals in both the acute $(n=12)$ and subacute $(n=14)$ phases were found to be significantly increased over the acute $(n=10)$ and subacute $(n=10)$ controls. The right ventricular cavity area of the acute group was significantly increased over the control group. Animals dying in the subacute phase had significantly increased right and left ventricular cavity areas compared to the control group. In addition, changes in the wall thickness of the heart of both the acute and subacute groups were noted (Table 1).

Forty-one percent of the animals survived $\mathrm{RbCV}$ infection (chronic). The principal pathologic lesions of animals in the chronic phase included myocyte hypertrophy and interstitial and replacement fibrosis and myocarditis. The degree and number of inflammatory lesions varied greatly between sections examined in different portions of the heart and between different animals. In all chronic animals the degree of interstitial and replacement fibrosis was mild, with the greatest concentration occurring in the papillary muscles ${ }^{7}$. The degree of myocyte hypertrophy also varied among chronic animals. The chronic animals were divided into two groups, slight $(16-20 \mu \mathrm{m})(\mathrm{n}=13)$ and moderate $(21$ $25 \mathrm{um})(\mathrm{n}=9)$ based upon mean myocyte diameters (Table 1). The myocyte diameters of both the slight and moderate groups were significantly increased over the controls. In addition, the degree of myocyte hypertrophy of the moderate group was significantly increased over the slight group. The mean measurements for heart weights, cavity areas and wall thickness of the chronic animals and their uninfected controls are also summarized in Table 1 . Heart weights and HW/BW ratios were significantly increased over the control group. The right ventricular cavity area of both the slight and moderate groups were also significantly increased. There was no significant difference between the left ventricular cavity areas of the control and slight groups. However, the left ventricular cavity area of the moderate group was significantly increased over both the control and slight groups. The thickness of the right wall, left wall and interventricular septum of animals in the chronic phase showed no significant differences from the control group.

Table 1. Mean heart weights and morphometric measurements of RbCV infected rabbits 6,7 (reprinted with permission of the University of Chicago Press)

\begin{tabular}{|c|c|c|c|c|c|c|c|}
\hline $\begin{array}{c}\text { Mean } \\
\text { measurements }\end{array}$ & $\begin{array}{l}\text { Acute } \\
\text { control }\end{array}$ & $\begin{array}{c}\begin{array}{c}\text { Acute } \\
\text { infected }\end{array} \\
\end{array}$ & $\begin{array}{l}\text { Subacute } \\
\text { control }\end{array}$ & $\begin{array}{l}\text { Subacute } \\
\text { infected }\end{array}$ & $\begin{array}{l}\text { Chronic } \\
\text { control }\end{array}$ & $\begin{array}{c}\text { Chronic } \\
\text { slight }\end{array}$ & $\begin{array}{l}\text { Chronic } \\
\text { moderate }\end{array}$ \\
\hline $\begin{array}{l}\text { Heart } \\
\text { weight } \\
\text { (g) } \\
\end{array}$ & $\begin{array}{c}6.1 \\
(+/-0.3) \\
\end{array}$ & $\begin{array}{c}{ }^{8} \\
{ }^{8} \\
(+/-1.4) \\
\end{array}$ & $\begin{array}{c}6.1 \\
(+/-0.5) \\
\end{array}$ & $\begin{array}{c}8^{8} \\
(+/-1.6) \\
\end{array}$ & $\begin{array}{c}6.6 \\
(+/-0.9) \\
\end{array}$ & $\begin{array}{c}8 .{ }^{a} \\
(+/-1.2) \\
\end{array}$ & $\begin{array}{c}8.2^{a} \\
(+/-0.5) \\
\end{array}$ \\
\hline $\begin{array}{l}\text { Heart } \\
\text { weight/ } \\
\text { Body } \\
\text { weight } \\
-3 \\
\left(\begin{array}{lll}x & 10\end{array}\right) \\
\end{array}$ & $\begin{array}{c}2.2 \\
(+/-0.2)\end{array}$ & $\begin{array}{c}3^{a} \\
(+/-0.2)\end{array}$ & $\begin{array}{c}2.2 \\
(+/-0.2)\end{array}$ & $\begin{array}{c}3.5 \\
(+/-0.6)\end{array}$ & $\begin{array}{c}2.0 \\
(+/-0.2)\end{array}$ & $\begin{array}{c}{ }^{a} \\
2.6 \\
(+/-0.2)\end{array}$ & $\begin{array}{c}2^{a} \\
(+/-0.2)\end{array}$ \\
\hline $\begin{array}{l}\text { Right } \\
\text { ventricular } \\
\text { cavity area } \\
2 \quad 6 \\
(\text { um } \times 10) \\
\end{array}$ & $\begin{array}{c}38.9 \\
(+/-11.8)\end{array}$ & $\begin{array}{c}{ }^{a} \\
(+/-39.8)\end{array}$ & $\begin{array}{c}41.22 \\
(+/-13)\end{array}$ & $\begin{array}{c}146.2^{a} \\
(+/-51.8)\end{array}$ & $\begin{array}{c}44.8 \\
(+/-13.8)\end{array}$ & $\begin{array}{c}7^{74.34}{ }^{b} \\
(+/-21.9)\end{array}$ & $\begin{array}{c}116.1^{a} \\
(+/-53)\end{array}$ \\
\hline $\begin{array}{l}\text { Left } \\
\text { ventricular } \\
\text { cavity area } \\
2 \quad 6 \\
(u m \times 10) \\
\end{array}$ & $\begin{array}{c}57.1 \\
(+/-6.1)\end{array}$ & $\begin{array}{c}65.3 \\
(+/-21.9)\end{array}$ & $\begin{array}{c}59.9 \\
(+/-10.5)\end{array}$ & $\begin{array}{c}{ }^{77.5} \\
(+/-20.3)\end{array}$ & $\begin{array}{c}61.92 \\
(+/-22.6)\end{array}$ & $\begin{array}{c}63.61 \\
(+/-21.5)\end{array}$ & $\begin{array}{c}94.6 \\
(+/-40.1)\end{array}$ \\
\hline $\begin{array}{l}\text { Right wall } \\
\text { thickness } \\
\text { (um) }\end{array}$ & $\begin{array}{c}2087 \\
(+/-270) \\
\end{array}$ & $\begin{array}{c}{ }^{a} \\
1545 \\
(+/-249) \\
\end{array}$ & $\begin{array}{c}2065 \\
(+/-284) \\
\end{array}$ & $\begin{array}{c}{ }^{a} \\
1295 \\
(+/-318) \\
\end{array}$ & $\begin{array}{c}1265 \\
(+/-236) \\
\end{array}$ & $\begin{array}{c}1501 \\
(+/-294) \\
\end{array}$ & $\begin{array}{c}1508 \\
(+/-230) \\
\end{array}$ \\
\hline $\begin{array}{l}\text { Left wall } \\
\text { thickness } \\
\text { (um) }\end{array}$ & $\begin{array}{c}4186 \\
(+/-545) \\
\end{array}$ & $\begin{array}{c}4369 \\
(+/-512) \\
\end{array}$ & $\begin{array}{c}4410 \\
(+/-617) \\
\end{array}$ & $\begin{array}{c}3^{b} \\
(+/-718) \\
\end{array}$ & $\begin{array}{c}3196 \\
(+/-639) \\
\end{array}$ & $\begin{array}{c}3594 \\
(+/-618) \\
\end{array}$ & $\begin{array}{c}3522 \\
(+/-429) \\
\end{array}$ \\
\hline $\begin{array}{l}\text { Septum } \\
\text { thickness } \\
\text { (um) }\end{array}$ & $\begin{array}{c}4470 \\
(+/-676) \\
\end{array}$ & $\begin{array}{r}4419 \\
(+/-740) \\
\end{array}$ & $\begin{array}{c}4470 \\
(+/-503) \\
\end{array}$ & $\begin{array}{c}\mathbf{a} \\
3597 \\
(+/-603) \\
\end{array}$ & $\begin{array}{c}3365 \\
(+/-583) \\
\end{array}$ & $\begin{array}{c}3698 \\
(+/-577) \\
\end{array}$ & $\begin{array}{c}3367 \\
(+/-521) \\
\end{array}$ \\
\hline $\begin{array}{l}\text { Myocyte } \\
\text { diameter } \\
\text { (um) }\end{array}$ & ND & ND & ND & ND & $\begin{array}{c}15.42 \\
(+/-1.7)\end{array}$ & $\begin{array}{c}18.64^{a} \\
(+/-1.15)\end{array}$ & $\begin{array}{c}21.822^{a} \\
(+/-1.48)\end{array}$ \\
\hline
\end{tabular}

$a$ = significant difference from control $(p<0.01)$

$\mathrm{b}=$ significant difference from control $(\mathrm{p}<0.05)$

ND $=$ Not done 
ECGs recorded prior to infection and in control animals demonstrated sinus rhythm with a mean HR of $228 \pm 38$ and $218 \pm 37$ beats/min respectively and a mean $R$ wave voltage of $0.38 \pm 0.11$ and $0.44 \pm 0.14 \mathrm{mV}$ respectively, similar to previously reported values 9 . During the acute phase of RbCV infection, sinus tachycardia (mean HR $=277 \pm$ 18 beats/min) developed and $R$ wave values in lead II were slightly depressed $(0.30 \pm 0.11$ $\mathrm{mV}$ ) (Figure 1). In addition to the sinus tachycardia and reduced $R$ wave voltages, $S T$ segment changes, supraventricular premature complexes, and Mobitz type II $2^{\circ} \mathrm{AV}$ block were occasionally observed during the acute phase (Table 2). The subacute phase was marked by persistent sinus tachycardia $(284 \pm 38$ beats $/ \mathrm{min})$ and significant reductions in $R$ wave voltages in lead II $(0.17 \pm 0.06 \mathrm{mV})$ (Figure 1). $T$ wave voltage was reduced and generally paralleled the QRS voltage changes during the subacute phase. Occasional supraventricular tachyarrhythmias and $2^{\circ} \mathrm{AV}$ block type persisted in some animals, and some animals displayed isolated ventricular premature depolarizations (Table 2). The chronic phase of infection was characterized by return of the sinus rate to baseline values and resolution of the QRS voltage changes, but persistence of ST segment changes, $T$ wave changes, ventricular and supraventricular arrhythmias and $2^{\circ} \mathrm{AV}$ block (Table 2) in some animals.

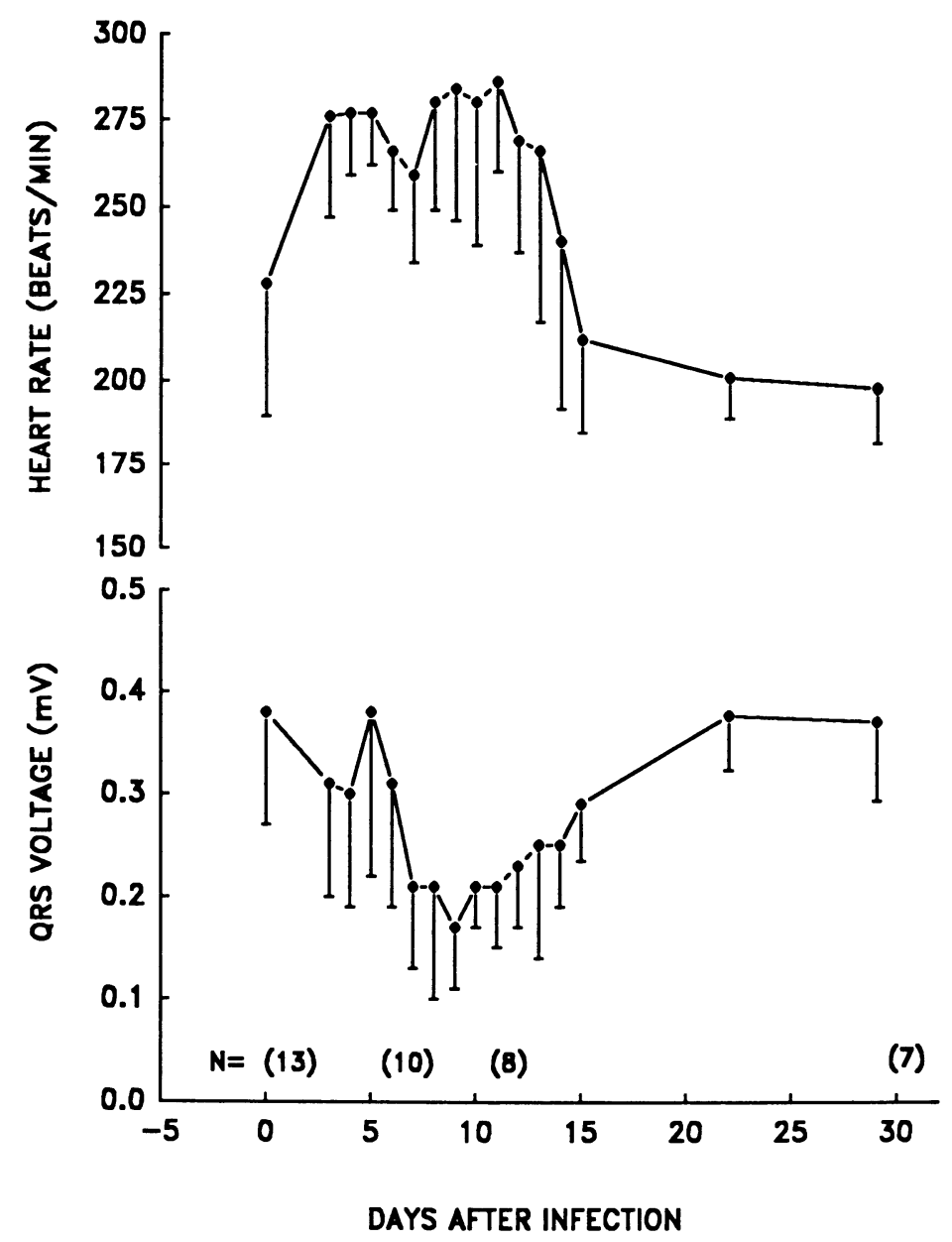

Figure 1. Mean heart rate and QRS voltage vs day of infection in RbCV infected rabbits. 
Table 2. ECG changes in 9 rabbits after infection with $\mathrm{RbCV}$.

\begin{tabular}{|c|c|c|c|c|}
\hline ECG changes & $\begin{array}{c}\text { Acute } \\
\text { (days 2-5) } \\
n=9\end{array}$ & $\begin{array}{c}\text { Subacute } \\
\text { (days } 6-12 \text { ) } \\
n=7\end{array}$ & $(>$ & $\begin{array}{l}2 \text { days } \\
n=6\end{array}$ \\
\hline$T$ wave changes ${ }^{a}$ & $8(89 \%)$ & $6(86 \%)$ & 3 & $(50 \%)$ \\
\hline ST segment changes ${ }^{b}$ & $2(22 q)$ & $0(0 \%)$ & 2 & $(33 \%)$ \\
\hline \multicolumn{5}{|l|}{ Rhythm disturbances } \\
\hline $\begin{array}{l}\text { Ventricular premature } \\
\text { complexes }\end{array}$ & $0(0 \%)$ & $1(148)$ & 1 & $(17 \%)$ \\
\hline $\begin{array}{l}\text { Supraventricular } \\
\text { premature complexes }\end{array}$ & 1 (118) & $1(14 \%)$ & 2 & $(338)$ \\
\hline Sinus arrthythmia & $0(0 \%)$ & $0(0 \%)$ & 2 & $(338)$ \\
\hline \multicolumn{5}{|l|}{ Conduction defects } \\
\hline $\begin{array}{l}2^{\circ} \text { Atrioventricular } \\
\text { block-type II } \\
\text { Mobitz }\end{array}$ & 1 (11\%) & $1(14 \%)$ & 2 & $(338)$ \\
\hline
\end{tabular}

b. Elevation or depression.

\section{DISCUSSION}

Human coronaviruses, in part responsible for the common cold, have also been implicated in more serious human afflictions such as pneumonia, perimyocarditis, meningitis and radiculitis and in the development of multiple sclerosis 10,11 . A unique model for virus-induced heart disease has been described in our laboratory6,7. Rabbit coronavirus is probably an enveloped RNA virus that is morphologically and antigenically related to Group I human and animal coronaviruses 8 . RbCV infection in rabbits results in the development of myocarditis and CHF with a $60 \%$ mortality rate. About $41 \%$ of the survivors of rabbit coronavirus infection may develop DCM at a later stage in life. The similarities between RbCV-induced myocarditis and DCM and human disease suggest that it is an excellent animal model for human heart disease 6,7

Rabbit coronavirus infection was divided into three phases: acute, subacute, and chronic based upon day of death and/or pathologic findings 6,7 . The acute phase of infection (days 2-5) was characterized by right ventricular dilation, pulmonary edema, and degeneration and necrosis of myocytes 6 . Electrocardiographic findings in the acute phase included sinus tachycardia, slightly lower QRS voltages, T wave and ST segment changes compatible with myocardial injury and apparently infrequent supraventricular arrhythmias and $\mathrm{AV}$ conduction disturbances. In contrast, $38 \%$ of the animals early in EMC infection, had complete AV block ${ }^{12}$. Because ECGs were recorded intermittently for brief periods, the actual frequency and pathophysiologic significance of arrhythmias during the course of $\mathrm{RbCV}$ infection remains speculative. Rabbits dying in the acute phase of infection did so suddenly and without moderate or severe clinical signs of $\mathrm{CHF}$, raising the possibility that acute $\mathrm{RbCV}$ infection increases ventricular vulnerability. If this is true, the RbCV model should provide an interesting and rare opportunity to study sudden cardiac death (SCD) due to viral infection. SCD is defined as death caused by underlying coronary or noncoronary heart disease in which the subject is completely asymptomic or experiences symptoms one hour or less before death. In the United States there are approximately 300,000 SCD per year of which approximately 20 percent are due to noncoronary heart disease including acute viral myocarditis and idiopathic dilated cardiomyopathy 13 . Viral infection of the heart (cardiac viral neuropathy) has also been implicated in the pathogenesis of SCD in humans ${ }^{14}$. Studies have shown that major risk factors for SCD include cardiac enlargement, nonspecific $T$ wave and ST segment abnormalities, and ventricular premature beats, 15 most of which are detected early after RbCV infection. 
During the subacute phase of the infection (days 6-12) an additional $30 \%$ of the rabbits died. Rabbits dying during the subacute phase showed more severe myocyte degeneration and necrosis than during the acute phase, with calcification of myocytes and infiltration of inflammatory cells into the myocardium. These severe histopathologic changes were accompanied by dramatic biventricular dilation and eccentric hypertrophy of the myocardium. Postmortem venous congestion of the liver and lungs suggested the presence of congestive heart failure in these animals 6 . Electrocardiographic findings in the subacute phase included sinus tachycardia with low voltage QRS complexes compatible with pleural effusion, and occasional animals with supraventricular and/or ventricular arrhythmias and/or AV block. These ECG findings are comparable to the variety and type of changes seen in humans with myocarditis and CHF as well as those observed in other animal models of myocarditis and $\mathrm{CHF}^{1,12,16,17}$.

Survivors of $\mathrm{RbCV}$ infection (chronic phase) were divided into two groups based upon the degree of myocyte hypertrophy. Animals in the moderate group exhibited pathologic and electrocardiographic changes consistent with the development of DCM. Pathologic changes included an enlarged heart, biventricular dilation, myocyte hypertrophy, fibrosis and myocarditis ${ }^{7}$. The ECG findings were nonspecific but taken with the pathologic evidence were consistent with the development of DCM and myocarditis. Nonspecific ST-T wave changes were frequently seen as well as rhythm and conduction disturbances. In humans with DCM and in the EMC model of DCM, arrhythmias and conduction defects have also been frequently detected 3,12 .

Most of the information concerning the pathogenesis and mechanisms of virusinduced myocarditis and DCM has been obtained from animal models following CBV and EMC infection in mice 4,5 . With the few model systems available to study the sequence of events leading from viral infection to the development of myocarditis and DCM, the $\mathrm{RbCV}$ model will no doubt provide considerable insight into the mechanisms by which enveloped RNA viruses induce heart disease.

\section{REFERENCES}

1. J. Woodruff, Am J Pathol. 101:427 (1980)

2. K. Leslie, R. Blay, C. Haisch, et al, Clin Microbiol Rev. 2:191 (1989)

3. W. Roberts, R. Siegel, and B. McManus, Am J Cardiol. 60: 1340 (1987)

4. M. Reyes, K. Ho, F. Smith, and A. Lerner, J Infect Dis. 144:232 (1981)

5. A. Matsumori and C.Kawai, in: "Viral Heart Disease, H. Bolte ed. Springer-Verlag, NY (1984)

6. S. Edwards, J. Small, J. Geratz, L. Alexander, and R. Baric, J Infect Dis. 165:134 (1992)

7. L. Alexander, J. Small, S. Edwards and R. Baric, J Infect Dis. 166 (1992)

8. J. Small, L. Aurelian, R. Squire, et al, Am J Pathol. 95:709 (1979)

9. C. Nelson, W. Waggoner, and P Gastonguay, Am J Physiol. 207:1107 (1964)

10. H. Riski, and T. Hovi, J Med Virol. 6:259 (1980)

11. R Murray, B. Brown, D Brian, and G. Cabric, Ann Neurol. 31:525 (1992)

12. C. Kishimoto, A. Matsumori, M. Ohmae, et al, J Am Coll Cardiol 3:1461. (1984)

13. R. Myerburg and A. Castellanos, in: Heart Disease. E. Brunwald ed. W.B. Saunders Company, Philadelphia (1988)

14. T. James and K. Imamura, Jpn Heart J. 22:447 (1981)

15. W. Castelli et al. in: The Prevention of Sudden Cardiac Death. J. Kostis and M. Sanders, eds. Wiley-Liss, NY. (1990)

16. T. Monath, G. Kemp, C. Cropp, and F. Chandler, J Infect Dis. 138:59 (1978)

17. T. Hoshino, A Matsumori, C. Kawai, and J. Imai, Jpn Circul J. 46:1305 (1982) 